OPEN ACCESS

Edited by:

Gabriela Topa,

National Distance Education

University (UNED), Spain

Reviewed by:

Gilbert Ernest Franco,

Beacon College, United States Graham R. Davidson,

Retired, Melbourne, VIC, Australia

${ }^{*}$ Correspondence:

Elsheba K. Abraham elsheba@vt.edu

Specialty section: This article was submitted to Organizational Psychology, a section of the journal

Frontiers in Psychology

Received: 19 July 2018 Accepted: 11 April 2019 Published: 03 May 2019

Citation: Abraham EK, McCusker ME and Foti RJ (2019) Competing Conversations: An Examination of Competition as Intrateam Interactions. Front. Psychol. 10:970. doi: 10.3389/fpsyg.2019.00970

\section{Competing Conversations: An Examination of Competition as Intrateam Interactions}

\author{
Elsheba K. Abraham ${ }^{1 *}$, Maureen E. McCusker ${ }^{2}$ and Roseanne J. Foti ${ }^{1}$ \\ ${ }^{1}$ Virginia Polytechnic Institute and State University, Blacksburg, VA, United States, ${ }^{2}$ Consortium Research Fellows Program, \\ Alexandria, VA, United States
}

Intrateam competition is an inherently social and interactional process, yet it is not often studied as such. Research on competition is mostly limited to studying it as an individual state and assumes that the resulting team outcomes are equivalent across different competition types. Often overlooked in competition research are the means through which competition can lead to constructive outcomes for the team. Constructive competition occurs when the primary motivation is not to win at the expense of others, but rather to make social comparisons and gain knowledge of relative competence. This study furthers insight into constructive competition by studying its interpersonal characteristics as it develops within a team, and its impact on task conflict, perceived performance, and team satisfaction. The conversations of 24 student project teams were recorded over 4 weeks and analyzed, operationalizing competition as an attempt to exert control and influence on the team. Each individual then provided sociometric ratings of perceived performance of each team member, and rated the level of task conflict and satisfaction of the team. The effects of competition on perceived performance and team satisfaction, both directly and indirectly through task conflict, were examined. Findings demonstrated a negative direct effect of competition on the range of perceived performance ratings, and a positive indirect effect of competition on team satisfaction as mediated through task conflict. The study broadens understanding on the construct of competition and underscores the positive implications competition can bring to the teams.

Keywords: constructive competition, organizational discourse analysis, social interdependence, team satisfaction, team performance, task conflict

\section{INTRODUCTION}

"Great things in business are never done by one person; they're done by a team of people." - Steve Jobs

Regardless of the type of organization or the industry, a majority of companies today are converging toward team-based business models (McDowell et al., 2016). Teams enable organizations to diversify their range of expertise and skills, giving them the flexibility to adapt to the current market and maintain a competitive edge (Kozlowski and Bell, 2003). Prior teams 
researchers have found positive relationships between team effectiveness and organizational performance (e.g., Banker et al., 1996; Hamilton et al., 2003; Srivastava et al., 2006; Barrick et al., 2007). These findings align with what is intuitively known amongst employees; $91 \%$ of individuals across industries agree that teams are central to an organization's success (Martin and Bal, 2015). Put simply, work teams are ubiquitous and are an essential part of our professional life. Thus, it is critical for organizations to have effective, efficient, and highly functioning teams.

Teams are characterized as a collection of two or more individuals who interact socially and perform interdependent tasks within an organizational context (Kozlowski and Bell, 2003). Team performance is not only a function of completing tasks assigned to the team, but also includes the results from team processes and individual effort (Katzenbach and Smith, 1993). Thus, how individuals interact with others can influence a team's success (Marks et al., 2001). There is a level of social interdependence present within a team, as individuals share common goals and carry out actions that can influence the outcomes experienced by others (Stanne et al., 1999). Competition occurs if there is a negative relationship of goal attainment between two individuals - that is, if a goal sought by an individual clashes with goal achievement of someone else (Deutsch, 1949, 1962, 1969). Opposing goal structures induce individuals to act out in self-interest; it influences their interactions patterns and encourages actions that improve chances of obtaining personal goals at the expense of others, ultimately leading to competitive outcomes for the team (Johnson, 2003; Deutsch, 2011). This understanding between the conditions in a team and subsequent interactions that result in competition is the basic premise of the Social Interdependence Theory (Deutsch, 1949; Johnson, 2003).

As one of the major types of interdependencies observed in organizations (Tjosvold, 1986), competition has long been of focal interest for scholars studying team performance and states. Some of the earliest work can be traced back to the 1920s when Whittemore studied competition amongst workers in a printing task (Whittemore, 1924). Since then, research on how competition can influence the overall functioning of the team and subsequently team performance has expanded. The literature spans across domains from social and educational psychology (e.g., Julian and Perry, 1967; Johnson et al., 1979) to organizational conflict management (e.g., Alper et al., 2000; Lu et al., 2010) and sports psychology (e.g., Scanlan and Lewthwaite, 1984; Ntoumanis et al., 2007). Despite this, there is still some debate whether competition results in positive (Michaels, 1977; Young et al., 1993) or negative (Grossack, 1954; Kohn, 1992) outcomes. In fact, reviews of the research literature point to both (Miller and Hamblin, 1963; Johnson et al., 1981; Stanne et al., 1999).

We believe the lack of clarity of the team competitionoutcome relationship stems from at least three issues, which we aim to address in this study. The first issue relates to how competition is operationalized. Different types of competition are often thought to be equivalent, which is problematic as the nature and outcomes from competition can vary according to competition type (Stanne et al., 1999). The second issue pertains to the measurement of competition as a construct. Deutsch (1949) highlights the dynamic, process-oriented nature of competition; it is a process of team interactions, influenced not only by the task but also by prior behaviors of team members that can impact future actions. However, competition is seldom studied as a process. Rather, it is most often measured through self-report, which provides only a single, often biased, snapshot of the competitive process. Third, there is a general disregard for the social context in which team interactional processes are embedded (Cronin et al., 2011). This is problematic, as competition is closely related to the interactions that occur from the social interdependencies present within a team (Deutsch, 1969).

Thus, the purpose of this study is to take a process-oriented approach to studying competition based on observable dyadic interactions within a team's natural context. In doing so, we aim to obtain deeper insight into the specific nature of competition, how it influences outcomes such as perceived performance and team satisfaction, as well as the means through which these relationships emerge. This study contributes to the literature of intrateam competition, both methodologically and theoretically. Methodologically, we present a novel, processoriented approach to capturing competition within a team, based in organizational-discourse analysis (Fairhurst and UhlBien, 2012). Theoretically, we shed more clarity on the relationships between intrateam competition and team outcomes to better understand how and when competition is beneficial or detrimental for organizational units.

\section{Intrateam Competition}

Competition can exist in many forms and levels - between units or collectives (interteam competition; Johnson and Johnson, 1991), between individuals (interpersonal competition; Deutsch, 1949), and between individuals in a collective (intrateam competition; Julian et al., 1966). Intrateam competition is understood as the encouragement of inter-individual competition and comparison between individuals in a unit (Ntoumanis et al., 2007), and it is commonly discussed in relation to goals (Deutsch, 1949). That is, interaction patterns between individuals vary as a function of perceived goal interdependence. Cooperative intrateam interactions occur when individual team members each possess interrelated goals and rely on each other to work toward shared goals; on the other hand, competitive intrateam interactions occur when individual goals are mutually exclusive and efforts are focused on increasing chances of attaining a personal goal (Deutsch, 1969, 2011).

Goals are fundamental regulators of human action (Locke et al., 1981) and thus are constant driving forces of behavior. In the context of teams, individuals learn to collaborate with one another to progress toward an overarching goal, such as successfully completing a team project. However, while team members work toward completing a team-level goal, they may also have personal goals they try to achieve concurrently (Brouwer, 2016). Thus, intrateam competition occurs when an individual in a unit perceives a negative outcome 
interdependence; that is, the progress toward one goal results in movement away from someone else's goal (Deutsch, 2011).

\section{Intrateam Competition as a Process}

Researchers often study competition as an independent, stable construct divorced from the reality in which it is couched (Sommer, 1995). However, this deviates from how competition was originally conceptualized as a construct. In his seminal work on the topic, Deutsch (1949) identified the fundamental connection between competition and interpersonal relations, highlighting the importance of studying "the interactions between individuals, (and) the group process that emerges as a consequence of a cooperative or competitive social situation" (Deutsch, 1949, p. 1). Not only is competition a dynamic construct, but it also occurs within a team that is a dynamic entity in it of itself, where tasks, goals, and often members change frequently (Cronin et al., 2011).

To study competition accurately, researchers must align its operationalization with its conceptualization as a dynamic process (Kozlowski and Klein, 2000). While the sophistication of methodology and analytic techniques has vastly improved, utilization of these dynamic methods of capturing behavior is still lacking within the competition literature. The use of self-report to assess competition dominates, and most studies measure competition as a global construct and not within the context of the specific team (Gelfand et al., 2012). This is problematic since competition is dependent on various contextual factors that can vary across teams. Furthermore, self-report measures fail to capture the nature of interactions between individuals in an organization as they unfold over time (Knapp et al., 1988).

As interpersonal communication is at the core of smallgroup processes (Bonito and Sanders, 2011), measuring verbal interactions is one method of getting closer to understanding processes as they unfold in teams (Fairhurst and Uhl-Bien, 2012; Lehmann-Willenbrock and Allen, 2018; McCusker et al., 2018). This process-oriented measurement approach captures the social and interactional process mechanisms of competition. In the past decade, there has been a growing emphasis on studying interactions in situ to deepen our understanding on a variety of organizational constructs such as leadership (Wodak et al., 2011), employee attitudes (Meinecke et al., 2017), team coordination (Kauffeld and Lehmann-Willenbrock, 2012), and team diversity (Harvey, 2013). When intrateam competition occurs, interactions vary often as individuals try to balance maximizing individual performance relative to the group while ensuring the level of team performance (and thereby individual performance) is not negatively impacted (Miller and Hamblin, 1963). Hence, measuring competition as a process through interpersonal interactions enables proper emphasis on the social dynamics of intrateam competition. In this regard, one particularly valuable research strategy that could be applied is organizational discourse analysis (ODA; Putnam and Fairhurst, 2001; Grant et al., 2004). In ODA, verbal interactions between individuals are recorded or observed, and then coded and analyzed to uncover patterns of communication that reflect individual, dyadic and team phenomena. This process-oriented approach provides a means for better understanding of the full development of particular constructs instead of relying on snapshots based on an individual's perception of what happened.

To the authors' knowledge, there have been no other empirical studies within the organizational sciences that have studied intrateam competition through the lens of ODA, and more specifically, interpersonal interactions. Interpersonal dynamics carry a big impact on team outcomes, especially when participation from team members is necessary for a task (Tjosvold, 1986); hence, we seek to understand the team outcome implications for competition in the context of our study by observing intrateam interactions. The present study measures competition through in situ communicative interactions between team members as they worked together to accomplish a team task over time. As the aim of the study was to better clarify the impact of competition on team effectiveness, we focused on two of its most prevalent indicators in team literature: performance and team satisfaction (e.g., Gladstein, 1984; Costa, 2003).

\section{Team Outcomes of Competition}

The research literature has found mixed results regarding the outcomes of competition on teams. Some research has found that competition has a positive impact. It encourages individuals to be more engaged with a task (Goldman et al., 1977) and to outperform their peers (Julian and Perry, 1967; Scott and Cherrington, 1974). However, the advantages associated with competition are typically more pronounced when the task can be completed independently and is routine (Deutsch, 1949; Erev et al., 1993), as competition enhances speed (Sommer, 1995; Beersma et al., 2003). Despite some of these positive findings regarding competition, the consensus is that aside from the specific conditions of a task that requires little collaboration between individuals, intrateam competition does not lead to advantageous team outcomes (Johnson et al., 1981; Stanne et al., 1999). Competition has been found to result in poorer performance for complex, and highly interdependent tasks in which two or more people are required to complete a task (Miller and Hamblin, 1963; Tjosvold, 1986; Stanne et al., 1999). Research also shows competition taints communication when individuals collaborate on a task (Deutsch, 1969, 2011), and increases hostile behavior and suspicion as individuals seek to preserve their personal goals (Deutsch, 1949).

Thus, intrateam competition has been found to result in both positive and negative outcomes for teams. While one explanation for this discrepancy may be the type of task, as discussed above, we believe an alternative explanation is the over-simplistic conceptualization of the construct of competition. There remains a fair amount of ambiguity regarding the conceptualization and operationalization of competition in the literature (Stanne et al., 1999). Nonetheless, there is now a growing body of research that investigates the different dimensions and forms of competition (Johnson and Johnson, 1974, 1991; Tjosvold et al., 2003, 2006). Competition can be classified into two types: zerosum competition, where the winner-takes-all, and constructive competition (also known as appropriate competition), where winning is not given much importance (Stanne et al., 1999). Research on zero-sum competition dominates the field (Stanne et al., 1999; Tjosvold et al., 2003), yet both types of competition 
carry very different implications for the team. The lack of empirical work on constructive competition fails to reflect how commonly it occurs, from classrooms (Johnson and Johnson, 1974) to organizations (Tjosvold et al., 2003) as well to what it means for individuals and collectives. To fill this gap in the literature and heed calls to further develop theory on competition (Stanne et al., 1999), we focus this study on constructive competition and its impact on team processes and states.

\section{Constructive Competition}

A distinct characteristic of constructive competition distinguishing it from zero-sum competition is the relative weakness of negative outcome interdependence experienced (Stanne et al., 1999). In other words, although there is still an opposing goal structure between individuals, it is not the primary motivation to engage in competition. This phenomenon occurs when winning is not the top priority for individuals within the unit, the rules and process for winning is fair and specific, and everyone has a reasonable chance of achieving a specified goal (Johnson and Johnson, 1991; Stanne et al., 1999; Johnson, 2003; Tjosvold et al., 2003). Additionally, competition is constructive when individuals can monitor their progress by making comparisons of their performance relative to others. Social competition motivates individuals to expend greater effort and perform better than others in the team (Nicholls, 1984; Sommer, 1995); thus, these comparisons of competence, instead of winning, become the impetus for competing with others (Johnson and Johnson, 1974; Stanne et al., 1999).

Empirical research in this domain demonstrates that constructive competition leads to positive outcomes, even in situations or types of tasks where competition may not seem particularly advantageous. For example, in a study of Chinese managers and subordinates working in business organizations, Tjosvold et al. (2003) found that intellectually stimulating tasks were related to increased learning and self-efficacy when constructive competition was present. Additionally, perceiving an intrinsic motivation in the competitive rival who engages in competition due to enjoyment of the process itself can positively influence subsequent interactions. As such, there is an increase in constructiveness of competition experienced, as measured by task-related and affective-related benefits (Chang and Chen, 2012).

\section{Competition and Perceived Performance}

Project teams often must complete tasks that are highly interdependent, requiring constant communication and coordination to refine ideas and efforts (Mathieu et al., 2014). Intrateam competition may manifest as individuals attempt to gain status by dominating actions and influencing team decisions (Zhao, 2015). However, if the desire to achieve overall team success is prioritized, it can lead to effective collaboration with others in the team - building off of ideas and engaging in productive conversations where relevant information is shared with all (Deutsch, 1990). When there is a basis of cooperation that underlies interactions within the team, constructive competition is likely to occur and can motivate individuals to display the skills and knowledge needed to progress team effort and increase effectiveness in completing a task (Johnson and Johnson, 1991; Tjosvold et al., 2003). The increase in effort and effectiveness may spur individuals to engage further in social comparisons to assess their competence. Thus, team members would be more perceptive to the performance of their peers. Accordingly, we predict:

Hypothesis 1: Intrateam competition will have a negative direct effect on team members' perceptions of each other's performance.

\section{Competition and Team Satisfaction}

Team satisfaction is closely linked to intrateam processes. It is influenced not only by the nature of the task, but also from the interactions between team members (Van Der Vegt et al., 2001). When project teams work together on a task for an extended period of time, individuals have to account for not only the short-term advantages for engaging in competition but its implication in the long run. Long-term goals, such as establishing a rapport with team members through multiple project meetings, can increase the strength of an overall cooperative goal and subsequently encourage constructive competition (Tjosvold et al., 2003; Sheridan and Williams, 2011). Thus, competitive interactions in this context can lead to constructive outcomes to the team such as more positive relationships and desire to participate in the team (Tjosvold et al., 2003). There is still incentive to invest efforts in a task, but without the negative strain that is associated with competing solely to win (Wittchen et al., 2011). Additionally, when there is an unambiguous competitive climate, individuals can clearly assess their progress relative to others while knowing the nature of competition and what is needed to achieve their goal. Individuals are less likely to feel anxious or unhappy about team processes that occur (Johnson and Johnson, 1991). Hence, a sense of contentment with the team likely emerges.

Hypothesis 2: Team competition will have a positive direct effect on team satisfaction.

\section{The Role of Task Conflict}

Though distinct concepts, intrateam competition and conflict are often confounded (Deutsch, 1969; Tjosvold, 1998). While intrateam competition can be conceptualized colloquially as a rivalry of goals, intrateam conflict can be understood as a clash in activities (Deutsch, 1969). The literature distinguishes between three types of team conflict: relationship, process, and task conflict (Jehn and Mannix, 2001). First, relationship conflict refers to discord and animosity between individuals within a team and is often associated with negative affect toward team members. Second, process conflict refers to disagreements about divvying up responsibilities and work among team members so that the task gets accomplished (Jehn, 1997). Third, task conflict refers to disagreements about opinions and ideas related to the task (Amason and Sapienza, 1997). Relationship and process conflict have consistently been found to be detrimental for both teams and individuals (Baron, 1991; Pelled, 1996; Jehn et al., 1999). However, task conflict has been found to be positively associated with a variety of team outcomes, including team satisfaction and 
performance (Hoffman and Maier, 1961; Korsgaard et al., 1995; Amason, 1996). Some researchers suggest the positive effect of task conflict on performance occurs because task conflict affords team members the opportunity to voice their opinions and discuss issues related to the task (e.g., Amason, 1996; Simons and Peterson, 2000; Wellman, 2013). Related are findings that teams are generally better able to manage task conflict, over relationship and process conflict. For example, in a study of 65 autonomous, newly formed teams, Behfar et al. (2008) found that the clear majority $(71 \%)$ of teams that experienced consistent (and even increasing) levels of team performance and satisfaction over time effectively managed and resolved task conflict. In comparison, only one and $33 \%$ of the teams were able to address relationship and process conflict, respectively.

Despite the evidence that task conflict positively impacts team performance and satisfaction, little is known about the role of team competition in this relationship. Early research on teams and collectives suggest competition between groups of people drives interteam conflict, as proposed by Marx's (1847) Conflict Theory and Realistic Conflict Theory (Sherif, 1958). At a more micro level, past research has found that competition is positively related to different forms of conflict (Brouwer, 2016). Competitive processes often induce behaviors that further perpetuate competitive interactions and facilitate conditions under which conflict emerges (Deutsch, 1994). As intrateam constructive competition is oriented toward addressing competing goals in order to push the task forward, it likely results in conflicting opinions about the task itself, or task conflict. Thus, if task conflict is positively associated with performance and satisfaction, and intrateam competition is positively associated with task conflict, it is likely that intrateam competition indirectly impacts team performance and satisfaction through task conflict.

Hypothesis 3a: Intrateam competition will have a negative indirect effect on team members' perceptions of each other's performance through task conflict.

Hypothesis 3b: Intrateam competition will have a positive indirect effect on team satisfaction through task conflict.

\section{MATERIALS AND METHODS}

\section{Sample and Procedure}

Participants were 119 students (68\% female) from three semesters of the same psychology course at a large, southeastern university. Participants were recruited from the classroom and received course credit for their participation in the study, and all students from all three semesters consented to participate. The course required a team project component, so all participants were randomly assigned to teams of four to six ( $n=24$ teams), stratified based on gender and academic major to ensure heterogeneity in teams. No participant reported being friends or acquaintances with any teammate prior to the first day of class. Teams were assigned a total of three different team projects, which they were to complete over the 12 weeks in the semester (4 weeks per project). The current study focused on the first project only, which entailed conducting an analysis of one team member's previously held job. Teams worked together in class for 50-min once per week to complete the project. To minimize the amount of time participants spent working on the project outside of the classroom, participants were urged to complete as much of the project as possible in class.

To capture competitive interactions unfolding within teams, each team was recorded using audio recorders placed on each team's table throughout the weekly class time devoted to working on projects. For coding purposes, prior to beginning project discussions, each team member identified his/herself verbally so that voices could be matched with names during the coding (discussed below). At end of the semester, all participants were sent a link to a questionnaire including relevant study variables and completed sociometric ratings of all other team members' contributions to the projects.

This study was carried out in accordance with the recommendations of the Virginia Tech Institutional Review Board Policies and Procedures, following the ethical principles described in The Belmont Report and in applicable federal regulations. The protocol was approved by the Virginia Tech Institutional Review Board. All subjects gave written informed consent in accordance with the Declaration of Helsinki.

\section{Measures \\ Competition}

Intrateam competition was operationalized as a pattern of communication between dyads in teams. Drawing from communication literature and ODA (e.g., Courtright et al., 1989) focusing on interpersonal interaction (interaction process analysis; Bales and Strodtbeck, 1951), the operational unit of analysis was a dyadic "interact" (Weick, 1979), or a reciprocal verbal communication from one person back to another (i.e., utterance from $\mathrm{A}$ to $\mathrm{B}$ and from $\mathrm{B}$ back to $\mathrm{A}$ ).

\section{Coding Interacts}

All task-relevant verbal utterances representing a complete thought - or an attempt at a complete thought - were coded using an amended version of Fairhurst's Relational Control Coding Scheme (1989). Non-task relevant communication was not coded. Each utterance included a code for the speaker, the recipient ${ }^{1}$ and type of utterance. Utterances could take on three different types: An assertion of control toward the recipient, or a one-up move ( $\uparrow)$, an acquiescence of control toward the recipient, or a one-down move $(\downarrow)$, or a neutralization of control toward the recipient, or a one-across move $(\rightarrow)$. Assertion of control, or one-up moves, were the only types of interest for this study. As defined in previous relational control research (Fairhurst et al., 1995; de La Peña et al., 2012), an interact is a sequential pair of moves between dyad members. Thus, in this study, a competitive interact was defined as a sequential pair of oneup moves. The amount of intrateam competition was calculated as the percentage of competitive interacts occurring within the

\footnotetext{
${ }^{1}$ Utterances directed toward the team as a whole were removed from the analyses, as an interact requires a response from the recipient, and a team in its entirety cannot provide a response.
} 
team over the course of the 4 weeks (i.e. number of competitive interacts/total interacts).

All verbal interactions were coded directly from the audio recordings, as opposed to transcriptions of the interactions, a process which has been found to more accurately capture interpersonal processes than coding based on transcriptions of data alone (Nicolai et al., 2010). All coding was conducted using INTERACT software (Mangold, 2010), a coding and statistical analysis program that provides a platform to develop codebooks, code behavioral data, and analyze interaction based data. Prior to coding, coders engaged in extensive training, practice and feedback, codebook refinement and tests of agreement. Formal training included the following: approximately $15 \mathrm{~h}$ of education on relational control coding and research (e.g., Courtright et al., 1989) and definitions of the codes included in the codebook; and approximately $25 \mathrm{~h}$ of coding practice and feedback, both independently together. Throughout this time, inclusion criteria for what to code, definitions of codes and how to code each utterance were refined.

Upon completion of training, pairwise agreement was calculated among all coders. As recommended for sequential behavioral observation research for this type of data (Bakeman et al., 2009; Lehmann-Willenbrock and Allen, 2018), agreement was calculated in multiple steps. The first step consisted of testing agreement on the unitization of utterances, or whether an utterance was "code-able." The second step consisted of testing agreement on the content of relational control. Agreement was calculated using Light's (1971) Kappa, which is an algebraic mean of all pairwise kappa values. Results showed adequate agreement across all three coding categories $(k=0.83$ for unitization; $k=0.72$ for relational control). To maintain levels of agreement, coders met bi-weekly throughout the coding process ( $\sim 20$ weeks) to collectively discuss questions, concerns or idiosyncrasies. Following recommendations by Omerod and Ball (2017) to check for coding "drift" in agreement after substantial periods of time, the previous procedure was replicated upon completion of $2 / 3$ of the audio recordings. Results of this coding drift study revealed higher Light's Kappa values for all three coding categories $(k=0.77,-0.84)$.

\section{Task Conflict}

Task conflict was measured using Behfar et al.'s (2011) Task Conflict Scale. The 3-item scale, which measures an "awareness of differences in viewpoints and opinions about the team's task" (Behfar et al., 2011, p. 128) has previously been found to be reliable (alpha $=0.84$; Behfar et al., 2011). Responses are made on a five-point scale (never to all of the time) and include questions such as, "To what extent does your team argue the pros and cons of different options?"

\section{Team Satisfaction}

Team satisfaction was measured using Hackman's (1988) Team Satisfaction Scale. The 3-item scale has previously been found to be reliable (alpha $=0.95$; Cameron and Allen, 2014). Responses are made on a five-point scale (strongly disagree to strongly agree) and include questions such as, "Generally speaking, I'm very satisfied with the team.”

\section{Perceived Performance}

To measure team perceived performance, team members were asked to rate the degree to which each of their peers contributed to completing the project. Participants were asked to assign a rating from 70 to 115 to each team member, reflecting each team member's effort in completing the project. Each participant was then assigned a score based on the average of the peers' evaluations. To translate the individual level scores to the collective level, we calculated the range of team members' scores. Thus, higher scores represented a larger discrepancy (range) in team members' contributions, as rated by their team members, while lower team scores represented a lower discrepancy in this regard.

\section{RESULTS}

The means, standard deviations, reliability coefficients, and correlation coefficients of the variables of interest are reported in Table 1. All variables were aggregated and analyzed at the team level, as the primary purpose of this study is to examine how the interactions of dyads within a collective combine to impact the collective perceptions of team phenomena. This is also aligned with our theoretical hypotheses that focused on team outcomes. Due to the small sample size of the study, a more lenient criteria for significance is used, reporting all values that have a significance of $p<0.1$ (Lavrakas, 2008). To facilitate the interpretation of our results, we also report the $\mathrm{R}^{2}$ effect sizes for the direct effects calculated from univariate regression analyses. According to Cohen et al. (2003), the effect size conventions for variance explained are $0.02,0.13$, and 0.26 for a small, medium, and large effect size, respectively. As for our indirect paths calculated from the mediation analyses, we report the standardized effect sizes for the indirect effects obtained from the STDYX standardization from Mplus. For single mediatormodels, standardized effect sizes are generally unbiased and can be interpreted clearly (Miočević et al., 2018). However, due to the lack of clear guidelines on what constitutes a small, medium or large effect size of indirect effects (Miočević et al., 2018), we refrain from commenting on the size of the standardized indirect effects.

The bivariate relationships show that competition had a significant, negative relationship with perceived performance

TABLE 1 | Means, standard deviations, correlations, and reliability coefficients.

\begin{tabular}{lrrrrrc}
\hline Variable & M & SD & $\mathbf{1}$ & $\mathbf{2}$ & $\mathbf{3}$ & $\mathbf{4}$ \\
\hline (1) Competition & -1.31 & 0.36 & - & & & \\
(2) Task conflict & 8.88 & 1.06 & $0.53^{* *}$ & $(0.75)$ & & \\
(3) Perceived performance & 1.15 & 0.84 & $-0.39^{*}$ & -0.80 & - & \\
(4) Satisfaction & 12.8 & 1.32 & 0.20 & $0.48^{*}$ & -0.32 & $(0.72)$
\end{tabular}

$N=24$. All variables are aggregated at team level. Numbers in the parentheses represent the Cronbach's alpha values for reliability. ${ }^{*} p<0.1$ and ${ }^{* *} p<0.05$. 


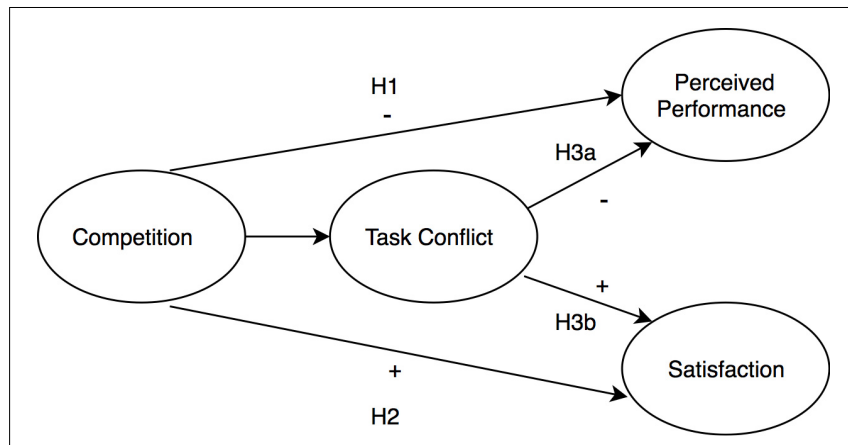

FIGURE 1 | Hypothesized model of proposed direct and indirect effects of competition on perceived performance and team satisfaction.

( $r=0.39$ and $p<0.10$ ). Given perceived performance was operationalized as the range of individuals' peer rating scores, the negative relationship suggests that as competition increases within the team, peer performance ratings for each team member were more balanced. That is, more competition was associated with less discrepancy in the degree to which each person was perceived, on average, to contribute to the team. There was no significant correlation between competition and team satisfaction $(r=0.20$, n.s.).

\section{Hypothesis Testing}

The hypothesized model, as pictured in Figure 1, was intended to be tested through a path model analysis conducted in Mplus (Version 8; Muthén and Muthén, 2017). As the hypothesized model was a just-identified or fully saturated model, model fit could not be assessed. Thus, the direct and indirect effects were tested separately to reduce the number of paths being estimated in the model and increase the degrees of freedom to examine model fit. Results for both models are depicted in Figure 2.

The direct effects of competition on each of the outcome variables were assessed through a simple linear regression. Results are reported in Table 2. Mirroring the correlations reported above, competition had a significant, negative effect on perceived performance $(\beta=-0.39$ and $p<0.10)$ and a medium effect size of $R^{2}=0.15$. Thus, Hypothesis 1 was supported.

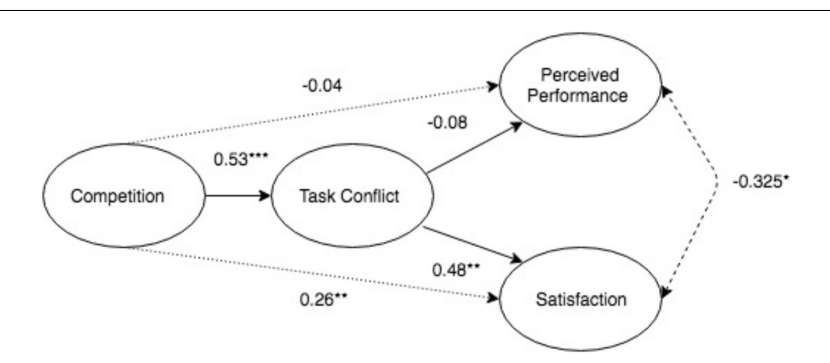

FIGURE 2 | Results of hypothesized model of the direct and indirect effects of competition. Standardized path estimates are reported. The indirect effects are represented by the dotted arrows, while the covariance between outcome variables is represented by the dashed arrow. ${ }^{*} p<0.1,{ }^{* *} p<0.05$, and $* * * p<0.001$.
However, competition had a no direct effect on team satisfaction $\left(\beta=0.20\right.$, n.s.) and a small effect size of $R^{2}=0.04$, failing to support Hypothesis 2.

Next, the model with the indirect effects was tested. Model fit was adequate, with $\chi^{2}(2)=6.08(p=0.05)$; SRMR $=0.095$, CFI $=0.76$. Significance of the indirect effects was evaluated using $95 \%$ confidence intervals from the bias-corrected estimates calculated from the 5000 bootstrapped samples drawn. Using bias-corrected bootstrapping estimates is recommended with small sample sizes, to obtain more accurate confidence intervals of the indirect effect (Efron and Tibshirani, 1994; Shrout and Bolger, 2002). Results showed that the indirect effect of competition on perceived performance was non-significant $(-0.04$; CI $=-0.39$ to 0.18 ; n.s. $)$; hence, Hypothesis $3 \mathrm{a}$ was not supported. As for the indirect effect of competition on team satisfaction, competition had a positive, indirect effect on satisfaction through task conflict $(0.26$; CI $=0.06$ to $0.48 ; p<0.05)$. Thus, Hypothesis $3 \mathrm{~b}$ was supported. Both the indirect and direct effects for the tested model are presented in Figure 2.

\section{DISCUSSION}

The vast majority of research on interpersonal competition focuses on its negative consequences for individuals and collectives (Tjosvold et al., 2003, 2006). This study, however, supports and contributes to a growing body of research finding that competition within teams can in fact have beneficial outcomes. Specifically, we found that the more that teams engaged in competitive interactions, the more equally they perceived their fellow team members' performance. Furthermore, these findings showed that competition did not directly impact team satisfaction, but instead affected team satisfaction through task conflict. However, the indirect effect of competition was not significant for perceptions of performance.

\section{Contributions and Implications}

We contribute to enriching both theoretical and empirical understanding of the constructive outcomes of competition and situate it within the broader literature of related constructs such as task conflict, performance, and satisfaction. Our findings highlight the positive effects of constructive competition. Teams benefit from competition when winning is not the main priority, competition is based upon clear and fair rules, each competitor has a comparable chance of winning, and there is opportunity to monitor performance relative to others. This study provides clearer insight into the impact of constructive competition within the natural constraints of a project team in a classroom.

The positive direct effect found between competition and perceptions of performance suggests that increased efforts to influence the team, such as with contributions of ideas or control over team-task processes, is advantageous for standardizing perceptions of performance across the team. This is an indication 
TABLE 2 | Results of regression analysis testing direct effects of competition on outcome variables.

\begin{tabular}{lcrr}
\hline Variable & $\boldsymbol{B}$ & SE & \multicolumn{1}{c}{$\boldsymbol{\beta}$} \\
\hline Competition & & & \\
Perceived performance & $-0.92^{*}$ & 0.46 & -0.39 \\
Team satisfaction & 0.73 & 0.78 & 0.20 \\
\hline
\end{tabular}

$N=24 . R^{2}$ for perceived performance $=0.15, R^{2}$ for team satisfaction $=0.04 .{ }^{*} p<0.10$.

of cohesion within the team, as everyone is believed to have invested effort on the task; as a result, assessment of a team member's performance is comparable with others within the team. Additionally, results demonstrate that competition and, in turn, task conflict are beneficial for teams, specifically in perceptions of satisfaction. This aligns our findings with past research that shows that effective task conflict management, characterized by open communication that is driven by facts and not emotions, leads to high team satisfaction (Behfar et al., 2008). Thus, when all individuals can contribute to the team and are engaged in constructive competition, an increase in intrateam interactions allows for a greater variety of viewpoints of the task to be discussed; this could ultimately lead to a better reflection of consensus with the team, and contribute to team satisfaction.

Unlike team satisfaction, we did not find an indirect effect of constructive competition on perceptions of performance through task conflict; however, results yielded a direct effect. While an indirect effect of competition on perceived performance was not found, relationships were in the hypothesized negative direction, suggesting the finding could, in part, be due to a low power to detect effects with the small sample of 24 teams. Alternatively, there could be other means through which competition impacts perceived performance. One plausible mechanism could be through achievement goals. Murayama and Elliot (2012) suggest an opposing processes model, in which they argue that the competition-performance relation is mediated by two different types of achievement goals: performanceapproach goals where individuals are motivated to outperform their peers, and performance-avoidance goals where individuals try not to perform poorly relative to others. In the context of the present study, an increase in competition heightens awareness of others' performance as individuals make social comparisons, which could potentially prompt individuals to adopt a particular type of achievement goal (Murayama and Elliot, 2012). Congruence between similar types of achievement goals within a team could potentially explain a convergence in perceptions in performance. Given the inherent relationship between individual goals and competition, goal congruence with regard to approach/avoidance goals presents a potential opportunity for fruitful research.

Additionally, our findings carry relevant implications beyond this study, as individuals may often find themselves in contexts where informal comparisons of performance are made instead of being in a winner-take-all situation. Our research coincides with other studies that have found the positive effects that constructive competition can have on teams. Constructive competition is generally found to increase performance across academic, workplace, and sports settings when competitors have a similar chance of succeeding (Worrell et al., 2016). For example, in a study examining intrateam competition amongst athletes, teams that had coaches who emphasized constructive competition during practices had better performance and greater enjoyment of athletes (Harenberg, 2014). In a completely different setting, Büki (2013) also demonstrated the positive effects of constructive competition in a group of Brazilian immigrants. Constructive competition facilitated integration between the immigrants and the host country, hence enabling the immigrant group to succeed in acculturation.

Moreover, this study contributes methodologically to the literature on constructive competition. First, most competition research either experimentally manipulates competition within teams or measures the construct using a self-report questionnaire, captured at some point after the fact. However, to measure competition as a process, and not a state (Deutsch, 1969), we drew from communication and discourse literature (Fairhurst and Uhl-Bien, 2012) to introduce a novel way to measure and thus operationalize constructive competition, which is better aligned with its conceptualization as a social process.

Second, collecting in situ data of newly formed teams working together in a naturalistic setting over time adds to the external validity of our findings. In modern-day organizations, competitive environments rarely resemble the exaggerated zero-sum competition often manipulated or assumed in the typical operationalization of competition. Given that organizations are gravitating toward more team-based, flat hierarchical structures, project-based teams are forced to work together to accomplish tasks. This environment certainly does not preclude intrateam competition from emerging, as humans' drive for status, power and control of resources underlie modern day intrateam social competition (Hays and Bendersky, 2015). However, such teams inherently require some degree of coordination and cooperation in order to complete projects and tasks. This reflects constructive competition (Tjosvold et al., 2006) or "coopetition" (Brandenburger and Nalebuff, 1996), which is more representative of the informal competition present in today's organizations. Our research design reflects this type of team setting and allows for measurement of a more realistic form of social competition; thus, provides a more direct application to organizations and practice.

Third, by operationally defining social competition as a dyadic verbal interaction using discourse, we treat competition not as a quality of a person or a situation, but rather as social processes manifested in the way a pair of individuals behave toward each other in context. We realize the limitations of aggregating dyadic level interactions to the team level (e.g., competition may have been primarily enacted by only one or two dyad members); however, with the exception of a few (e.g., Zhao, 2015), research does not tend to 
operationalize competition as the basic dyadic process that it is. We see this as an opportunity to provide novel insights into social competition, and by association, constructive competition at a relational level, as well as heed calls to advance dyadic level research in the organizational sciences (Krasikova and LeBreton, 2012).

\section{Limitations and Future Research}

As with any research, this study is certainly not without its limitations. First, while data in this study were collected over the course of 4 weeks, team sample size prevented the ability to test longitudinal hypotheses. Thus, competition data were aggregated over the course of 4 weeks. Given the paucity of research on competition over time, research capturing the emergence process of competition within teams as it unfolds over time is a fruitful avenue for future research. Researchers have suggested that interactional process dynamics are often characterized by positive and negative spirals that can escalate or diminish particular dyadic phenomena (DeRue and Ashford, 2010) and often result in affective contagion (Kelly and Barsade, 2001). Thus, a better understanding of how teams vary on trajectories of competition can shed light as to how and why competition develops, changes, and is managed within different types of teams.

Second, due to how the data were coded, we were unable to clearly distinguish between specific types of social competition that transpired among team members. For example, Zhao (2015) distinguished among three types of interpersonal competition behaviors, each with different intentions: the intention to convey superiority over another with regard to competence, participation, and connection to others. While our codebook was intended to capture relational control as opposed to behavioral intent, developing codebooks that provide more a more finegrained understanding of competitive interacts can provide a deeper understanding into interpersonal control manifests and unite disparate literature on the topics.

Another coding limitation was that all communication directed to the team in its entirety, as opposed to a specific individual, was excluded from analyses. This type of communication that is not directed to any particular individual in the team (e.g., talking to the room) has presented a challenge for small group researchers. While we recognize that control can be exercised toward all team members, the nature of an interact, as initially conceptualized by Weick (1979), is dyadic; thus we chose to eliminate all communications directed toward the team as a whole. We did, however, run the same analyses including team recipients and found similar results, so we feel justified in making this more conservative decision.

Despite these limitations, we believe our study lays a strong foundation for advancing the science of constructive competition. Given the relative novelty of the construct, there exist ample opportunities for advancing theoretical understanding. Particularly important, we believe, is research that focuses on additional cultural and contextual factors that might influence the relationships we uncovered in this and future research. As most of the research is conducted in laboratory/classroom settings and in North America (Tjosvold et al., 2003), identifying the contextual boundary conditions under which constructive competition unfolds is a critical condition for generalizability.

Aside from task conflict, another contextual factor that may mediate the effect of constructive competition on team performance is the degree to which a team is collectively or individualistically oriented. Due to the emphasis of constructive competition on fairness and equal chances of winning, the output of effort invested in a task should not be associated with a comparable amount of strain (Wittchen et al., 2011). However, individualistic teams that prioritize self-interest are likely driven by aversive competition (i.e., desire not to lose) as they anticipate the potential social consequences of losing; hence, they are more susceptible to strain when in competition (Wittchen et al., 2011). On the other hand, members in collectivistic teams who identify more strongly as a team than as separate individuals are likely to prioritize advancing the team. Hence, competition enhances task performance while any concerns about interpersonal issues or hostility that may arise from competitive processes are suppressed (Zhang et al., 2014). It is possible, then, that the saliency of an individual's identity compared to the team's identity influences how constructive competition is perceived. Those who adopt an individualistic mindset may emphasize winning more than those with a collectivistic perspective. It would be interesting to extend research by investigating the impact of different combinations of individualistic and collectivistic team members (e.g., homogenous collectivistic/individualistic; heterogenous), as one orientation could have more influence on team outcomes than the other.

In terms of potential moderators, one construct of interest is an organization's level of distributive justice, which refers to the perceived fairness of the ratio of outcomes received to efforts invested (Folger, 1977). Individuals perceive distributive justice when rewards received are in proportion to the amount of work put in and that ratio is comparable to the outcome/effort ratio of others in the organization. Because past research has established that behaving fairly is positively associated with constructive competition (Tjosvold et al., 2003) and satisfaction (McFarlin and Sweeney, 1992), it may be that what makes competition constructive versus destructive is the degree to which it is perceived as fair. If the "rules" are clear and specific, and everyone has a comparable likelihood of winning (i.e., fair), then competition is likely to be constructive, leading to healthy task (not relationship) conflict and positive outcomes for the unit. Further research ought to investigate the role of perceived fairness in relationships between constructive competition and team outcomes. Another moderator to consider is perceived task complexity. Research shows that perceived task complexity increases intrateam performance when zerosum competition is present; however, this relationship is limited to instances when the demands of the highly complex tasks do not exceed the ability of the individual to complete it (Brouwer, 2016). In the context of constructive competition, it is worth examining if task complexity would have a similar limiting effect on performance. Perhaps the opportunity to engage in comparisons of performance within the team could 
provide additional motivational resources to complete the task, thereby reducing the ceiling effect that task complexity could have on performance.

The area of constructive competition is rich with additional research questions, such as its temporal and social complexity. Previous research demonstrates that constructive competition encourages the desire to continue collaborating within the same team even after a task is completed (Tjosvold et al., 2003). Employing longitudinal research methods would allow us to examine how constructive competition and its impact on team outcomes changes over time. Additionally, although this study was purposefully conducted on project teams with no formal leadership, the presence of a formal hierarchy may impact the competition process. There is an extensive body of research supporting organizational conflict management, but the role of the leader in the conflict management and competition process is much in need of clarification (Behfar et al., 2011). Perhaps authentic leaders, who are highly self-aware and encourage positive self-development (Avolio and Gardner, 2005), can facilitate transparency within teams and thereby encourage the constructive effects of competition. Avenues for future research can include investigating the impact an individual's authentic leadership style has on team outcomes of constructive competition. Finally, both relationship and process conflict are pertinent to social and task processes that happen in a team (Jehn and Mannix, 2001). As both types of conflict are negatively associated with performance and relationship conflict with satisfaction (Jehn, 1997), it would be interesting to investigate if that trend is maintained if constructive competition occurs in a team.

\section{CONCLUSION}

The current study advances the study of competition and team outcomes in several ways. First, it is one of only a handful of studies to examine intrateam competition as an inherently social and interactional process. Second, it uses methodologies from

\section{REFERENCES}

Alper, S., Tjosvold, D., and Law, K. S. (2000). Conflict management, efficacy, and performance in organizational teams. Pers. Psychol. 53, 625-642. doi: 10.1111/ j.1744-6570.2000.tb00216.x

Amason, A. C. (1996). Distinguishing the effects of functional and dysfunctional conflict on strategic decision making: Resolving a paradox for top management teams. Acad. Manag. J. 39, 123-148. doi: 10.5465/256633

Amason, A. C., and Sapienza, H. J. (1997). The effects of top management team size and interaction norms on cognitive and affective conflict. J. Manag. 23, 495-516. doi: 10.1016/s0149-2063(97)90045-3

Avolio, B. J., and Gardner, W. L. (2005). Authentic leadership development: getting to the root of positive forms of leadership. Leadersh. Quart. 16, 315-338. doi: 10.1016/j.leaqua.2005.03.001

Bakeman, R., Quera, V., and Gnisci, A. (2009). Observer agreement for timed-event sequential data: a comparison of time-based and event-based algorithms. Behav. Res. Methods 41, 137-147. doi: 10.3758/BRM.41.1.137

Bales, R. F., and Strodtbeck, F. L. (1951). Phases in group problem-solving. J. Abnorm. Soc. Psychol. 46, 485-495. interpersonal communication to measure team member's verbal interactions. The benefit of studying actual verbal markers of a phenomenon such as competition between team members is that the obtained data are closer to the phenomena of interest, both conceptually and methodologically. Finally, our results highlighted the difference effects competition can have on team outcomes. In sum, this study shows that team competition is observable and impactful at the micro-level of team interaction processes. We hope that our findings will inspire future process research on competition and team dynamics.

\section{ETHICS STATEMENT}

This study was carried out in accordance with the recommendations of the Virginia Tech Institutional Review Board Policies and Procedures, following the ethical principles described in The Belmont Report and in applicable federal regulations, with written informed consent from all subjects. All subjects gave written informed consent in accordance with the Declaration of Helsinki. The protocol was approved by the Virginia Tech Institutional Review Board.

\section{AUTHOR CONTRIBUTIONS}

All authors collaborated to review the literature, design the study, conceptualize the model, and edit the manuscript. EA led the efforts to write the manuscript and organize the team. MM led the data collection and analysis efforts. RF provided the extensive feedback and contributed to writing the introduction and discussion.

\section{FUNDING}

Partial funding support was received the Virginia Tech Graduate Student Assembly's Graduate Research Development Program to purchase audio recorders.

Banker, R. D., Field, J. M., Schroeder, R. G., and Sintia, K. K. (1996). Impact of work teams on manufacturing performance: a longitudinal field study. Acad. Manag. J. 39, 867-890. doi: 10.5465/256715

Baron, R. A. (1991). Positive effects of conflict: a cognitive perspective. Empl. Responsibil. Rights J. 4, 25-36. doi: 10.1007/bf01390436

Barrick, M. R., Bradley, B. H., Kristof-Brown, A. L., and Colbert, A. E. (2007). The moderating role of top management team interdependence: implications for real teams and working groups. Acad. Manag. J. 50, 544-557. doi: 10.5465/amj. 2007.25525781

Beersma, B., Hollenbeck, J. R., Humphrey, S. E., Moon, H., Conlon, D. E., and Ilgen, D. R. (2003). Cooperation, competition, and team performance: toward a contingency approach. Acad. Manag. J. 46, 572-590. doi: 10.5465/30040650

Behfar, K. J., Mannix, E. A., Peterson, R. S., and Trochim, W. M. (2011). Conflict in small groups: The meaning and consequences of process conflict. Small Group Res. 42, 127-176. doi: 10.1177/1046496410389194

Behfar, K. J., Peterson, R. S., Mannix, E. A., and Trochim, W. M. (2008). The critical role of conflict resolution in teams: a close look at the links between conflict type, conflict management strategies, and team outcomes. J. Appl. Psychol. 93, 170-188. doi: 10.1037/0021-9010.93.1.170 
Bonito, J. A., and Sanders, R. E. (2011). The existential center of small groups: member's conduct and interaction. Small Group Res. 42, 343-358. doi: 10.1177/ 1046496410385472

Brandenburger, A. M., and Nalebuff, B. J. (1996). Co-Opetition. New York, NY: Doubleday Currency.

Brouwer, R. (2016). "When competition is the loser: The indirect effect of intrateam competition on team performance through task complexity, team conflict and psychological safety," in Paper presented at the meeting of the Hawaii International Conference on System Sciences (HICSS), Honolulu, HI.

Büki, L. N. (2013). "The role of competition in the integration of immigrants to the host society," in Paper Presented at the Fifteenth Annual CiCe Network Conference: Identities and Citizenship Education: Controversy, crisis and challenges, Lisbon.

Chang, K. I., and Chen, H. J. (2012). Effects of a rival's perceived motives on constructive competition within organizations: a competitive dynamics perspective. Asian J. Soc. Psychol. 15, 167-177. doi: 10.1111/j.1467-839x.2012. 01368.x

Cohen, J., Cohen, P., West, S. G., and Aiken, L. S. (2003). Applied Multiple Correlation/ Regression Analysis For the Social Sciences, 2nd Edn. Hillsdale, NJ: Erlbaum.

Costa, A. C. (2003). Work team trust and effectiveness. Pers. Rev. 32, 605-622. doi: 10.1108/00483480310488360

Courtright, J. A., Fairhurst, G. T., and Rogers, L. E. (1989). Interaction patterns in organic and mechanistic system. Acad. Manag. J. 32, 773-802. doi: 10.5465/ 256568

Cronin, M. A., Weingart, L. R., and Todorova, G. (2011). Dynamics in groups: are we there yet? Acad. Manag. Ann. 5, 571-612. doi: 10.1080/19416520.2011. 590297

de La Peña, C. M., Friedlander, M. L., Escudero, V., and Heatherington, L. (2012). How do therapists ally with adolescents in family therapy? An examination of relational control communication in early sessions. J. Counsel. Psychol. 59, 339-351. doi: 10.1037/a0028063

DeRue, D. S., and Ashford, S. J. (2010). Who will lead and who will follow? A social process of leadership identity construction in organizations. Acad. Manag. Rev. 35, 627-647. doi: 10.5465/amr.35.4.zok627

Deutsch, M. (1949). A theory of cooperation and competition. Hum. Relat. 2, 129-152.

Deutsch, M. (1962). “Cooperation and trust: Some theoretical notes," in Nebraska Symposium on Motivation, ed. M. Jones (Lincoln, NE: University of Nebraska Press), 275-320.

Deutsch, M. (1969). Conflicts: productive and destructive. J. Soc. Issues 25, 7-42. doi: 10.1111/j.1540-4560.1969.tb02576.x

Deutsch, M. (1990). Sixty years of conflict. Int. J. Conflict Manag. 1, 237-263. doi: 10.1108/eb022682

Deutsch, M. (1994). Constructive conflict resolution: principles, training, and research. J. Soc. Issues 50, 13-32. doi: 10.1111/j.1540-4560.1994.tb02395.x

Deutsch, M. (2011). “Cooperation and competition," in Conflict, Interdependence, and Justice: The Intellectual Legacy of Morton Deutsch, ed. P. Coleman (New York, NY: Springer), 23-40.

Efron, B., and Tibshirani, R. J. (1994). An Introduction to the Bootstrap. Boca Raton, FL: CRC Press.

Erev, I., Bornstein, G., and Galili, R. (1993). Constructive intergroup competition as a solution to the free rider problem: a field experiment. J. Exp. Soc. Psychol. 29, 463-478. doi: 10.1006/jesp.1993.1021

Fairhurst, G. T., Green, S., and Courtright, J. (1995). Inertial forces and the implementation of a socio-technical systems approach: a communication study. Organ. Sci. 6, 168-185. doi: 10.1287/orsc.6.2.168

Fairhurst, G. T., and Uhl-Bien, M. (2012). Organizational discourse analysis (ODA): examining leadership as a relational process. Leadersh. Quart. 23, 1043-1062. doi: 10.1016/j.leaqua.2012.10.005

Folger, R. (1977). Distributive and procedural justice: combined impact of voice and improvement on experienced inequity. J. Personal. Soc. Psychol. 35, 108119. doi: 10.1037//0022-3514.35.2.108

Gelfand, M. J., Leslie, L. M., Keller, K., and de Dreu, C. (2012). Conflict cultures in organizations: how leaders shape conflict cultures and their organizational-level consequences. J. Appl. Psychol. 97, 1131-1147. doi: 10.1037/a0029993

Gladstein, D. L. (1984). Groups in context: a model of task group effectiveness. Administr. Sci. Quart. 29, 499-517.
Goldman, M., Stockbauer, J. W., and McAuliffe, T. G. (1977). Intergroup and intragroup competition and cooperation. J. Exp. Soc. Psychol. 13, 81-88. doi: 10.1016/0022-1031(77)90015-4

Grant, D., Hardy, C., Oswick, C., and Putnam, L. (eds) (2004). Organizational Discourse. London: SAGE.

Grossack, M. M. (1954). Some effects of cooperation and competition upon small group behavior. J. Abnorm. Soc. Psychol. 49, 341-348. doi: 10.1037/h0054490

Hackman, J. R. (1988). "The design of work teams," in Handbook of Organizational Behavior, ed. J. W. Lorsch (Englewood Cliffs, NJ: Prentice Hall), 315-342.

Hamilton, B. H., Nickerson, J. A., and Owan, H. (2003). Team incentives and worker heterogeneity: an empirical analysis of the impact of teams on productivity and participation. J. Politic. Econ. 111, 465-497. doi: 10.1086/ 374182

Harenberg, S. (2014). As Iron Sharpens Iron: Understanding Competitive Processes in Elite Sport Teams. Ph.D. thesis, University of Regina, Regina.

Harvey, S. (2013). A different perspective: the multiple effects of deep level diversity on group creativity. J. Exp. Soc. Psychol. 49, 822-832. doi: 10.1016/j.jesp.2013. 04.004

Hays, N. A., and Bendersky, C. (2015). Not all inequality is created equal: effects of status versus power hierarchies on competition for upward mobility. J. Personal. Soc. Psychol. 108, 867-882. doi: 10.1037/pspi0000017

Hoffman, L. R., and Maier, N. R. (1961). Quality and acceptance of problem solutions by members of homogeneous and heterogeneous groups. J. Abnorm. Soc. Psychol. 62, 401-407. doi: 10.1037/h0044025

Jehn, K. A. (1997). A qualitative analysis of conflict types and dimensions in organizational groups. Adm. Sci. Q. 42, 530-557.

Jehn, K. A., and Mannix, E. A. (2001). The dynamic nature of conflict: a longitudinal study of intragroup conflict and group performance. Acad. Manag. J. 44, 238-251. doi: 10.5465/3069453

Jehn, K. A., Northcraft, G. B., and Neale, M. A. (1999). Why differences make a difference: a field study of diversity, conflict and performance in workgroups. Adm. Sci. Q. 44, 741-763.

Johnson, D. W. (2003). Social interdependence: interrelationships among theory, research, and practice. Am. Psychol. 58, 934-945. doi: 10.1037/0003-066X.58. 11.934

Johnson, D. W., and Johnson, R. T. (1974). Instructional goal structure: cooperative, competitive, or individualistic. Rev. Educ. Res. 44, 213-240. doi: $10.3102 / 00346543044002213$

Johnson, D. W., and Johnson, R. T. (1991). "Structuring competitive learning," in Learning Together and Alone: Cooperative, Competitive, and Individualistic Learning, 3rd Edn, eds D. Johnson and R. Johnson (Englewood Cliffs, NJ: Prentice-Hall), 97-126.

Johnson, D. W., Maruyama, G., Johnson, R., Nelson, D., and Skon, L. (1981). Effects of cooperative, competitive, and individualistic goal structures on achievement: a meta-analysis. Psychol. Bull. 89, 47-62. doi: 10.1037/0033-2909.134.2.223

Johnson, R. T., Johnson, D. W., and Tauer, M. (1979). The effects of cooperative, competitive, and individualistic goal structures on students' attitudes and achievement. J. Psychol. 102, 191-198. doi: 10.1080/00223980.1979.9923487

Julian, J., Bishop, D., and Fiedler, F. (1966). Quasi-therapeutic effects of intergroup competition. J. Personal. Soc. Psychol. 3, 321-327.

Julian, J. W., and Perry, F. A. (1967). Cooperation contrasted with intra-group and inter-group competition. Sociometry 30, 79-90.

Katzenbach, J. R., and Smith, D. K. (1993). The Discipline of Teams. Boston, MA: Harvard Business Press.

Kauffeld, S., and Lehmann-Willenbrock, N. (2012). Meetings matter: effects of team meetings on team and organizational success. Small Group Res. 43, 130-158. doi: 10.1177/1046496411429599

Kelly, J. R., and Barsade, S. G. (2001). Mood and emotions in small groups and work teams. Organ. Behav. Hum. Decis. Process. 86, 99-130. doi: 10.1006/obhd. 2001.2974

Knapp, M. L., Putnam, L. L., and Davis, L. J. (1988). Measuring interpersonal conflict in organizations: where do we go from here? Manag. Commun. Q. 1, 414-429. doi: 10.1177/0893318988001003008

Kohn, A. (1992). No Contest: The Case Against Competition, 2nd Edn. HoughtonMifflin: Boston, MA.

Korsgaard, M. A., Schweiger, D. M., and Sapienza, H. J. (1995). Building commitment, attachment, and trust in strategic decision-making teams: the role of procedural justice. Acad. Manag. J. 38, 60-84. doi: 10.5465/256728 
Kozlowski, S. W. J., and Bell, B. S. (2003). "Work groups and teams in organizations," in Handbook of Psychology: Industrial and Organizational Psychology, eds W. C. Borman, D. R. Ilgen, and R. J. Klimoski (New York, NY: Wiley), 333-375.

Kozlowski, S. W. J., and Klein, K. J. (2000). "A multilevel approach to theory and research in organizations: Contextual, temporal, and emergent processes," in Multilevel Theory, Research, and Methods in Organizations: Foundations, Extensions, and New Directions, eds K. J. Klein and S. W. J. Kozlowski (San Francisco, CA: Jossey-Bass), 3-90.

Krasikova, D. V., and LeBreton, J. M. (2012). Just the two of us: misalignment of theory and methods in examining dyadic phenomena. J. Appl. Psychol. 97, 739-757. doi: 10.1037/a0027962

Lavrakas, P. J. (2008). Encyclopedia of Survey Research Methods. Thousand Oaks, CA: SAGE Publications.

Lehmann-Willenbrock, N., and Allen, J. A. (2018). Modeling temporal interaction dynamics in organizational settings. J. Bus. Psychol. 33, 325-344. doi: 10.1007/ s10869-017-9506-9

Light, R. J. (1971). Measures of response agreement for qualitative data: some generalizations and alternatives. Psychol. Bull. 76, 365-377. doi: 10.1037/ h0031643

Locke, E. A., Shaw, K. N., Saari, L. M., and Latham, G. P. (1981). Goal setting and task performance: 1969-1980. Psychol. Bull. 90, 125-152. doi: 10.1037//00332909.90.1.125

Lu, J. F., Tjosvold, D., and Shi, K. (2010). Team training in china: testing and applying the theory of cooperation and competition 1. J. Appl. Soc. Psychol. 40, 101-134. doi: 10.1111/j.1559-1816.2009.00565.x

Mangold (2010). INTERACT Quick Start Manual V2.4. Available at: https://www. mangold-international.com/ (accessed April, 2015).

Marks, M. A., Mathieu, J. E., and Zaccaro, S. J. (2001). A temporally based framework and taxonomy of team processes. Acad. Manag. Rev. 26, 356-376. doi: 10.5465/amr.2001.4845785

Martin, A., and Bal, V. (2015). The State of Teams. [White Paper].

Marx, K. (1847). The Poverty of Philosophy. Paris: A. Franck.

Mathieu, J. E., Tannenbaum, S. I., Donsbach, J. S., and Alliger, G. M. (2014). A review and integration of team composition models: moving toward a dynamic and temporal framework. J. Manag. 40, 130-160. doi: 10.1177/ 0149206313503014

McCusker, M. E., Foti, R. J., and Abraham, E. K. (2018). "Leadership research methods: Progressing back to process," in What's wrong with Leadership? Improving Leadership Research and Practice, ed. R. E. Riggio (New York, NY: Routledge), 9-40.

McDowell, T., Agarwal, D., Miller, D., Okamato, T., and Page, T. (2016). Organizational Design: The Rise of Teams. [White paper]. Available at: https://www2.deloitte.com/insights/us/en/focus/human-capital-trends/2016/ organizational-models-network-of-teams.html (accessed July 18, 2018).

McFarlin, D. B., and Sweeney, P. D. (1992). Distributive and procedural justice as predictors of satisfaction with personal and organizational outcomes. Acad. Manag. J. 35, 626-637. doi: 10.2307/256489

Meinecke, A. L., Lehmann-Willenbrock, N., and Kauffeld, S. (2017). What happens during annual appraisal interviews? How leader-follower interactions unfold and impact interview outcomes. J. Appl. Psychol. 102, 1054-1074. doi: 10.1037/ ap10000219

Michaels, J. W. (1977). Classroom reward structures and academic performance. Rev. Educ. Res. 47, 87-98. doi: 10.3102/00346543047001087

Miller, L., and Hamblin, R. (1963). Interdependence, differential rewarding, and productivity. Am. Sociol. Rev. 28, 768-778.

Miočević, M., O’Rourke, H. P., MacKinnon, D. P., and Brown, H. C. (2018). Statistical properties of four effect-size measures for mediation models. Behav. Res. Methods 50, 285-301. doi: 10.3758/s13428-017-0870-1

Murayama, K., and Elliot, A. J. (2012). Further clarifying the competitionperformance relation: reply to D. W. Johnson et al. (2012). Psychol. Bull. 138, 1079-1084. doi: 10.1037/a0029606

Muthén, L. K., and Muthén, B. O. (2017). Mplus User's Guide, 8th Edn. Los Angeles, CA: Muthén \& Muthén.

Nicholls, J. G. (1984). Achievement motivation: conceptions of ability, subjective experience, task choice, and performance. Psychol. Rev. 91, 328-346. doi: 10. $1037 / / 0033-295 x .91 .3 .328$
Nicolai, J., Demmel, R., and Farsch, K. (2010). Effects of mode of presentation on ratings of empathic communication in medical interviews. Pat. Educ. Counsel. 80, 76-79. doi: 10.1016/j.pec.2009.10.014

Ntoumanis, N., Vazou, S., and Duda, J. L. (2007). "Peer-Created Motivational Climate," in Social Psychology in Sport, eds S. Jowette and D. Lavallee (Champaign, IL: Human Kinetics), 145-156.

Omerod, T. C., and Ball, L. J. (2017). "Cognitive Psychology," in The SAGE Handbook of Qualitative Research in Psychology, eds C. Wililg and W. S. Rogers (London: Sage).

Pelled, L. H. (1996). Demographic diversity, conflict, and work group outcomes: an intervening process theory. Organ. Sci. 7, 615-631. doi: 10.1287/orsc.7.6.615

Putnam, L. L., and Fairhurst, G. T. (2001). "Discourse analysis in organizations," in The New Handbook of Organizational Communication, eds F. M. Jablin and L. Putnam (Thousand Oaks, CA: Sage), 78-136.

Scanlan, T. K., and Lewthwaite, R. (1984). Social psychological aspects of competition for male youth sport participants: I. predictors of competitive stress. J. Sport Psychol. 6, 208-226. doi: 10.1123/jsp.6. 2.208

Scott, W. E., and Cherrington, D. J. (1974). Effects of competitive, cooperative, and individualistic reinforcement contingencies. J. Personal. Soc. Psychol. 30, 748-758. doi: 10.1037/h0037534

Sheridan, S., and Williams, P. (2011). Developing individual goals, shared goals, and the goals of others: dimensions of constructive competition in learning contexts. Scand. J. Educ. Res. 55, 145-164. doi: 10.1080/00313831.2011. 554694

Sherif, M. (1958). Superordinate goals in the reduction of intergroup conflict. Am. J. Sociol. 63, 349-356. doi: 10.1086/2 22258

Shrout, P. E., and Bolger, N. (2002). Mediation in experimental and nonexperimental studies: new procedures and recommendations. Psychol. Methods 7, 422-445. doi: 10.1037//1082-989x.7.4.422

Simons, T. L., and Peterson, R. S. (2000). Task conflict and relationship conflict in top management teams: the pivotal role of intragroup trust. J. Appl. Psychol. 85, 102-111. doi: 10.1037//0021-9010.85.1.102

Sommer, S. M. (1995). Social competition: identifying new perspectives and strategies for task motivation. Int. J. Conflict Manag. 6, 239-256. doi: 10.1108/ eb022764

Srivastava, A., Bartol, K. M., and Locke, E. A. (2006). Empowering leadership in management teams: effects on knowledge sharing, efficacy, and performance. Acad. Manag. J. 49, 1239-1251. doi: 10.5465/amj.2006.23478718

Stanne, M. B., Johnson, D. W., and Johnson, R. T. (1999). Does competition enhance or inhibit motor performance: a meta-analysis. Psychol. Bull. 125, 133-154. doi: 10.1037//0033-2909.125.1.133

Tjosvold, D. (1986). The dynamics of interdependence in organizations. Hum. Relat. 39, 517-540. doi: 10.1177/001872678603900603

Tjosvold, D. (1998). Cooperative and competitive goal approach to conflict: accomplishments and challenges. Appl. Psychol. 47, 285-313. doi: 10.1080/ 026999498377818

Tjosvold, D., Johnson, D. W., Johnson, R. T., and Sun, H. (2003). Can interpersonal competition be constructive within organizations? J. Psychol. 137, 63-84. doi: 10.1080/00223980309600600

Tjosvold, D., Johnson, D. W., Johnson, R. T., and Sun, H. (2006). Competitive motives and strategies: understanding constructive competition. Group Dyn. 10, 87-99. doi: 10.1037/1089-2699.10.2.87

Van Der Vegt, G. S., Emans, B. J., and Van De Vliert, E. (2001). Patterns of interdependence in work teams: a two-level investigation of the relations with job and team satisfaction. Pers. Psychol. 54, 51-69. doi: 10.1111/j.1744-6570. 2001.tb00085.x

Weick, K. E. (1979). The Social Psychology of Organizing (Topics in Social Psychology Series). Columbus, OH: McGraw-Hill Humanities.

Wellman, E. M. (2013). Enabling shared leadership in hierarchical groups. Ph.D. thesis, University of Michigan, Deep blue database, Lansing.

Whittemore, I. C. (1924). The influence of competition on performance: an experimental study. J. Abnorm. Psychol. Soc. Psychol. 19, 236-253. doi: 10.1037/ h0063946

Wittchen, M., Dick, R. V., and Hertel, G. (2011). Motivated information processing during intergroup competition: a model of intergroup competition 
effects on individual effort. Organ. Psychol. Rev. 1, 257-272. doi: 10.1177/ 2041386611398166

Wodak, R., Kwon, W., and Clarke, I. (2011). 'Getting people on board': discursive leadership for consensus building in team meetings. Discourse Soc. 22, 592-644. doi: 10.1177/0957926511405410

Worrell, F. C., Knotek, S. E., Plucker, J. A., Portenga, S., Simonton, D. K., Olszewski-Kubilius, P., et al. (2016). Competition's role in developing psychological strength and outstanding performance. Rev. Gen. Psychol. 20, 259-271. doi: 10.1037/gpr0 000079

Young, S. M., Fisher, J., and Lindquist, T. M. (1993). The effects of intergroup competition and intragroup cooperation on slack and output in a manufacturing setting. Account. Rev. 68, 466-481.

Zhang, S., Chen, G., Chen, X. P., Liu, D., and Johnson, M. D. (2014). Relational versus collective identification within workgroups: conceptualization, measurement development, and nomological network building. J. Manag. 40, 1700-1731. doi: 10.1177/0149206312439421

Zhao, H. (2015). Differentiated Cooperation and Competition Within. Ph.D.thesis, University of Iowa, Iowa.

Conflict of Interest Statement: The authors declare that the research was conducted in the absence of any commercial or financial relationships that could be construed as a potential conflict of interest.

Copyright (c) 2019 Abraham, McCusker and Foti. This is an open-access article distributed under the terms of the Creative Commons Attribution License (CC BY).

The use, distribution or reproduction in other forums is permitted, provided the original author(s) and the copyright owner(s) are credited and that the original publication in this journal is cited, in accordance with accepted academic practice. No use, distribution or reproduction is permitted which does not comply with these terms. 